\title{
Is Sacral Extension a Risk Factor for Early Proximal Junctional Kyphosis in Adult Spinal Deformity Surgery?
}

\author{
Sebastian Decker ${ }^{1,2}$, Renaud Lafage ${ }^{1}$, Christian Krettek ${ }^{2}$, Robert Hart ${ }^{3}$, Christopher Ames ${ }^{4}$, \\ Justin S. Smith ${ }^{5}$, Douglas Burton ${ }^{6}$, Eric Klineberg ${ }^{7}$, Shay Bess ${ }^{8}$, Frank J. Schwab ${ }^{1}$, \\ Virginie Lafage ${ }^{1}$, International Spine Study Group \\ ${ }^{1}$ Spine Service, Department of Orthopaedic Surgery, Hospital for Special Surgery, New York, NY, USA \\ ${ }^{2}$ Trauma Department, Hannover Medical School, Carl-Neuberg-Straße 1, Hannover, Germany \\ ${ }^{3}$ Department of Orthopaedic Surgery, Oregon Health \& Science University, Portland, OR, USA \\ ${ }^{4}$ Department of Neurological Surgery, University of California San Francisco, San Francisco, CA, USA \\ ${ }^{5}$ Department of Neurosurgery, University of Virginia Health System, Charlottesville, VA, USA \\ ${ }^{6}$ Department of Orthopaedic Surgery, University of Kansas Medical Center, Kansas City, KS, USA \\ ${ }^{7}$ Department of Orthopaedic Surgery, University of California Davis, Sacramento, CA, USA \\ ${ }^{8}$ Department of Orthopaedic Surgery, NYU Hospital for Joint Diseases, New York, NY, USA
}

Study Design: Retrospective cohort study.

Purpose: To investigate the role of sacral extension (SE) for the development of proximal junctional kyphosis (PJK) in adult spinal deformity (ASD) surgery.

Overview of Literature: The development of PJK is multifactorial and different risk factors have been identified. Of these, there is some evidence that SE also affects the development of PJK, but data are insufficient.

Methods: Using a combined database comprising two propensity-matched groups of fusions following ASD surgery, one with fixation to $S 1$ or S1 and the ilium (SE) and one without SE but with a lower instrumented vertebra of L5 or higher (lumbar fixation, LF), PJK and the role of further parameters were analyzed. The propensity-matched variables included age, the upper-most instrumented vertebra (UIV), preoperative sagittal alignment, and the baseline to 1 year change of the sagittal alignment.

Results: Propensity matching led to two groups of 89 patients each. The UIV, pelvic incidence minus lumbar lordosis, sagittal vertical axis, pelvic tilt, age, and body mass index were similar in both groups $(p>0.05)$. The incidence of PJK at postoperative 1 year was similar for SE (30.3\%) and LF (22.5\%) groups ( $p=0.207)$. The PJK angle was comparable $(p=0.963)$ with a change of $-8.2^{\circ}$ (SE) and $-8.3^{\circ}$ (LF) from the preoperative measures $(p=0.954)$. A higher rate of PJK after $S E(p=0.026)$ was found only in the subgroup of patients with UIV levels between T9 and T12.

Conclusions: Instrumentation to the sacrum with or without iliac extension did not increase the overall risk of PJK. However, an increased risk for PJK was found after SE with UIV levels between T9 and T12.

Keywords: Spine; Kyphosis; Scoliosis; Sacrum

Received Dec 4, 2018; Revised May 21, 2019; Accepted Jun 18, 2019

Corresponding author: Sebastian Decker

Trauma Department, Hannover Medical School, Carl-Neuberg-Straße 1, Hannover 30625, Germany

Tel: +49-511-5322026, Fax: +49-511-5325877, E-mail: decker.sebastian@mh-hannover.de 


\section{Introduction}

The prevalence of proximal junctional kyphosis (PJK) ranges between $5 \%$ and $40 \%$ and can have a substantial clinical impact, particularly after adult spinal deformity (ASD) surgery $[1,2]$, due to the complications that PJK poses. Adults with deformities have junctional issues adjacent to spinal fusion, one of which is PJK, which can be treated without surgery in many cases. However, in those that do, the rate of revision surgery is reported to range from $1.4 \%$ to $55 \%$, with the primary indications being pain, neurological deficits or resulting positive sagittal malalignment $[2,3]$.

While various definitions of PJK after ASD surgery are reported in the literature, a common definition is a kyphotic angle greater than $10^{\circ}$ between the upper-most instrumented vertebra (UIV) and upper-most instrumented vertebra $+2(\mathrm{UIV}+2)$ with an increase from preoperative alignment of at least $10^{\circ}$ in kyphosis [4,5]. A recent review showed that PJK most commonly (66\%) occurs within three months of surgery, and $80 \%$ of patients will develop it within 18 months [2]. Given the high incidence of PJK and its potentially disabling impact, the prevention of PJK is of considerable interest to spine surgeons. Accordingly, in-depth studies have been carried out and have identified various risk factors for the development of PJK.

Recently, there has been an emphasis on the importance of sagittal alignment. Patients who developed PJK after
ASD surgery exhibited considerable correction of the sagittal vertical axis (SVA). Thus, the risk of PJK increased with greater baseline deformity and consequently large surgical correction $[6,7]$. Other variables that affected PJK were high body mass index (BMI), older age, smoking and low bone density [8-10]. Whether the level of the UIV and the number of fused vertebrae increases the risk of developing PJK is currently being debated $[8,11,12]$. Additionally, other risk factors include implant construct rigidity and combined anterior/posterior fusion, as well as the use of iliac fixation [1].

If validated, the association between sacral extension (SE) and PJK is of significant importance (Fig. 1). Lumbosacral fusion rates after long posterior fusions for ASD have been shown to vary substantially, and isolated fusions to the sacrum without supplemental iliac fixation can be challenging due to implant failure (screw loosening) and sacral fractures [13-15]. Furthermore, sacroiliac joint overloading and degeneration due to increased strain of the fusions may be potential sources of long-term complaints after extension to S1 [16]. Consequently, many surgeons combine S1 screws with iliac screws to help protect $S 1$ pedicle screws that favor lumbo-sacral fusion rates [17-19]. Halting at the lumbar spine during ASD surgery, without sacral or even pelvic fixation, increases the strain at the lumbo-pelvic junction, which may cause distal junctional kyphosis.

There is evidence that sacral fixation is a risk factor for
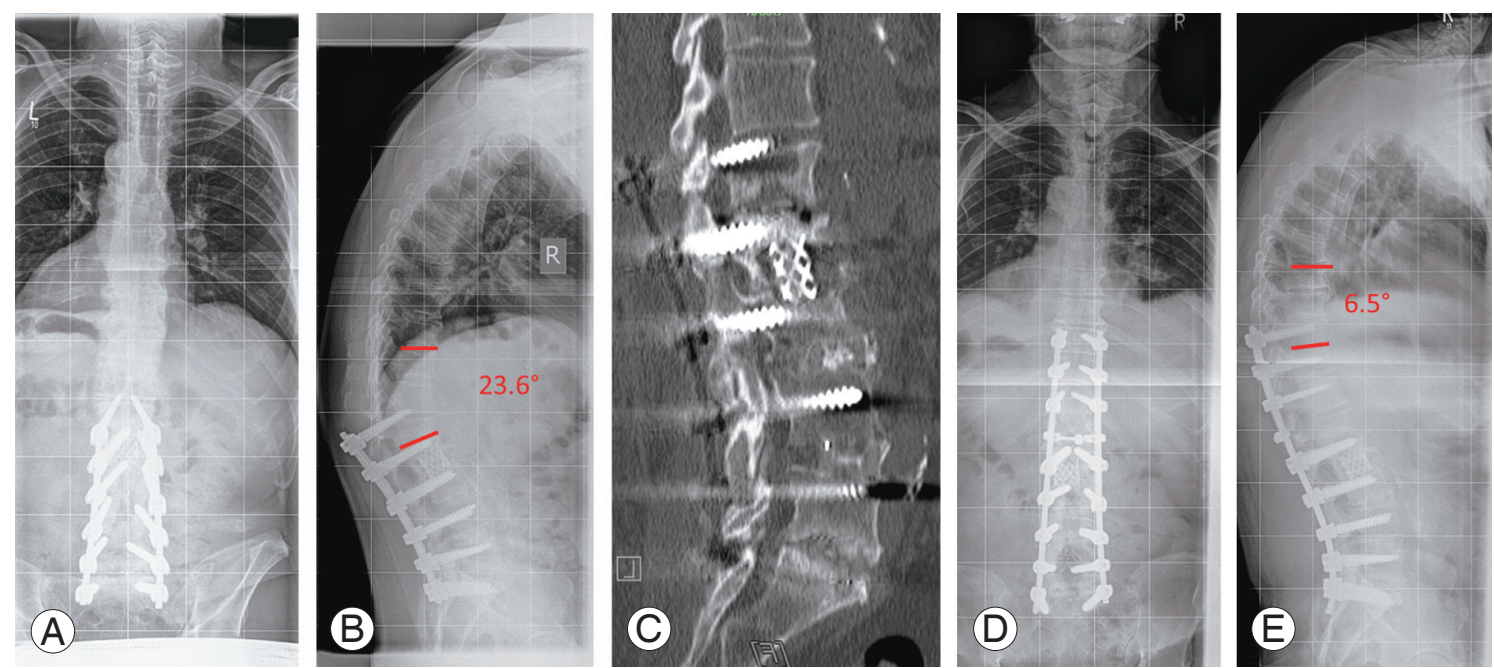

Fig. 1. 68-year old male with lumbar spinal deformity. Correction was performed at an external hospital from L1 to S1 (A, B). When presented to our hospital 3 months after surgery, PJK was already evident (B) with the complete screw cut out (C). The PJK angle was $23.6^{\circ}$, the SVA being $80 \mathrm{~mm}$ (B). Consequently, because of severe pain, fusion was performed from T10 to S1 (D, E). SVA after revision surgery was $48 \mathrm{~mm}$, lumbar lordosis $35^{\circ}$, thoracic kyphosis $56^{\circ}$, and PJK angle $6.5^{\circ}$. PJK, proximal junctional kyphosis; SVA, sagittal vertical axis. 
PJK. Multivariable logistic regression analysis revealed sacral fixation to be independently associated with PJK [20]. Further, Bridwell et al. [8] analyzed a consecutive series of 90 adult idiopathic/degenerative scoliosis patients and reported that a PJK angle $\geq 20^{\circ}$, although uncommon in daily practice, was significantly $(p=0.029)$ associated with fixation to the sacrum combined with iliac screws. In daily practice, we found patients without PJK following sacral fixation as well as many patients with PJK following SE (Fig. 2). We, therefore, hypothesized that SE increases the risk of PJK.

The objective of this study was to analyze the role of SE, in the development of PJK following ASD surgery, in patients with additional iliac fixation compared to lumbar fixation (LF), with the lowest instrumented vertebra (LIV) L5 or higher (Fig. 3).
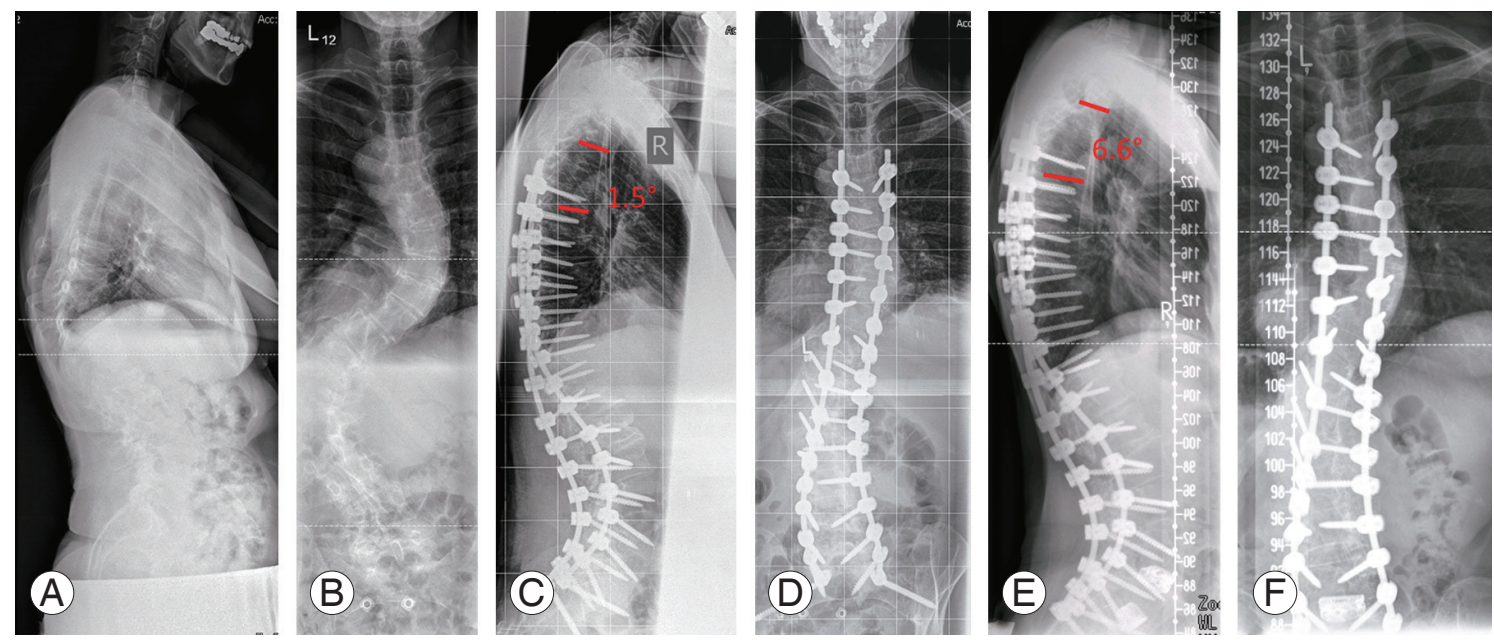

Fig. 2. 56-year old female with adult spinal deformity (A, B). Fusion surgery was performed from T4 to S2 alar-iliac in twostages - lumbar segmental release was performed the first stage and correction and fusion at the second stage (C, D). PJK angle after correction surgery was $1.5^{\circ}$ and 1 year after surgery, there was no-PJK (PJK angle, $\left.3^{\circ}\right)(\mathbf{E}, \mathbf{F})$. Patient was balanced in

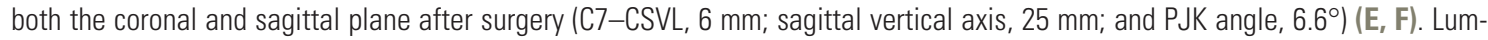
bar coronal deformity was corrected from $82^{\circ}$ to $17^{\circ}$ while thoracic coronal deformity was reduced from $61^{\circ}$ to $37^{\circ}$ (B, F). After correction and fusion, anterior lumbar interbody fusion was performed from $L 4$ to $S 1$ because of wide intervertebral discs. PJK, proximal junctional kyphosis; C7-CSVL, C7-central sacral vertical line.
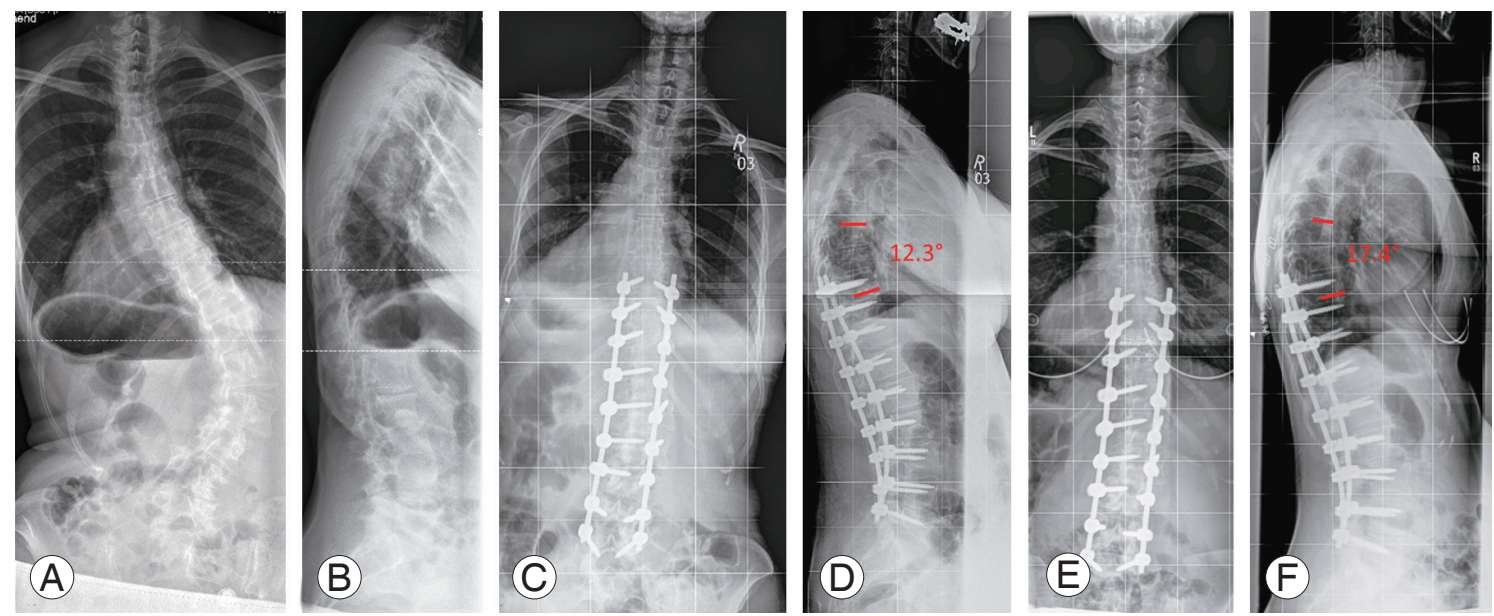

Fig. 3. 53-year old female with adult spinal deformity and mainly coronal imbalance (A, B). The C7-CSVL had an offset of $45 \mathrm{~mm}$ with a coronal lumbar deformity of $71^{\circ}$ (A). Sagittal balance was acceptable with an sagittal vertical axis of $50 \mathrm{~mm}(\mathrm{~B})$. Correction and fusion was performed from T9 to $L 5$ (C, D) and PJK angle was $12.3^{\circ}$ (D). Coronal and sagittal alignment were restored well with posture-related coronal imbalance postoperative. Coronal lumbar deformity was corrected to $27^{\circ}(\mathrm{C}, \mathrm{E})$. A year after surgery, posture-related coronal imbalance improved significantly with a C7-CSVL of $14 \mathrm{~mm}$ (E) and PJK angle, 17.4 (F). C7-CSVL, C7central sacral vertical line; PJK, proximal junctional kyphosis. 


\section{Materials and Methods}

This study was performed in accordance with local ethics committee guidelines. No explicit approval was needed for this study. Institutional review board approval was obtained before study initiation. Informed consent was obtained from each patient before being included into the database.

\section{Database}

This is a retrospective analysis of a multicenter combined database for ASD patients. A cohort of patients aged $>18$ years and diagnosed with ASD was enrolled from a prospectively collected database. ASD was defined radiologically by coronal Cobb angle $>20^{\circ}$, SVA $>5 \mathrm{~cm}$, pelvic tilt (PT) $>25^{\circ}$, or thoracic kyphosis (TK) $>60^{\circ}$. A second cohort of adult patients who received 3-column osteotomies in the thoracolumbar area was enrolled from a retrospectively collected database. The combined database consisted of both primary and revision cases. Patients with neuromuscular diseases, and infectious or malignant etiologies for ASD were excluded from the database. Patient demographics, surgery details, and health-related quality of life (HRQoL) at baseline and at each postoperative visit were obtained prospectively.

\section{Radiographic assessment}

All patients included in the database had postero-anterior and lateral 91.44-cm radiographs. Spino-pelvic alignment was measured using validated software (SpineView; ENSAM ParisTech, Paris, France) [21,22].

\section{Patient population}

After a retrospective analysis, we identified patients with a documented 1 year postoperative follow-up post-ASD surgery. These patients were grouped into those with SE or isolated LF. Patients with SE had undergone fusion down to S1 with potential iliac fixation whereas LF was defined by an LIV of L5 or higher.

\section{Propensity match}

To analyze the effect of SE on the risk of developing PJK in ASD surgery, two matched cohorts of patients were created for the LF and SE groups. The parameters for propensity matching were chosen based on known risk factors for PJK. Four parameters were included: age, UIV, preoperative sagittal alignment (pelvic incidence-lumbar lordosis, PI-LL), and the baseline to 1 year change in sagittal alignment (change in PI-LL postoperatively at 1 year, change PI-LL 1Y). The latter was included because the amount of surgical correction itself was associated with an increased risk for PJK, with the caveat that it was confounded by post-treatment conditions [6,7].

\section{Proximal junctional kyphosis}

The rate of PJK was identified for the SE and LF groups in general and for different UIV levels. Moreover, a subgroup analysis of patients who developed PJK was performed to evaluate the SVA in the LF and SE groups. For the LF and SE group analysis, we analyzed whether additional interbody fusion was associated with an additional risk of developing PJK. Moreover, age was compared between patients with and without PJK for both the LF and SE groups.

\section{Health-related quality of life}

For the assessment of the HRQoL, we used the modified Oswestry Disability Index (mODI) and the revised Scoliosis Research Society 22-item (SRS-22r) total questionnaire $[23,24]$. These tools were developed to measure function and pain. For both instruments, high validity and reliability have been established $[25,26]$.

\section{Statistical analysis}

Statistical analysis was performed using IBM SPSS ver. 20.0 (IBM Corp., Armonk, NY, USA). Differences between the $\mathrm{SE}$ and LF groups were calculated using unpaired $t$-tests, whereas paired $t$-tests were used to determine the changes of a parameter from baseline to 1 year. Interrelations of categorical variables were analyzed using contingency tables and chi-square tests. When appropriate, mean values and frequencies were calculated. All $p$-values $\leq 0.05$ were considered to be statistically significant.

\section{Results}

Propensity matching, summarized in Table 1 , led to the 
enrollment of 178 patients, 89 each assigned to the SE and LF groups. No significant differences were identified between the SE and LF groups with respect to patient age, UIV, PI-LL or the change PI-LL 1Y.

Gender distribution was similar in both groups: $77 \%$ and $78 \%$ of patients were female in the SE and LF groups, respectively. The mean BMI was $27.7 \pm 6.1 \mathrm{~kg} / \mathrm{m}^{2}$ (SE) and $26.6 \pm 7.0 \mathrm{~kg} / \mathrm{m}^{2}$ (LF) and did not significantly differ between groups ( $p=0.306$ ). The number of levels fused was $12.3 \pm 4.5$ (SE) and 10.7 $\pm 4.3(\mathrm{LF})$, and the difference was

Table 1. The propensity matching of patients with SE and those with LF

\begin{tabular}{lccc} 
Variable & SE & LF & $p$-value \\
Age $(y r)$ & $54.4 \pm 14.0$ & $54.1 \pm 15.4$ & 0.890 \\
Upper instrumented vertebra & $T 5 \pm 4.5$ & $T 5 \pm 4.6$ & 0.426 \\
\hline $\mathrm{PI}-\mathrm{LL}\left({ }^{\circ}\right)$ & $6.0 \pm 20.7$ & $6.2 \pm 19.8$ & 0.964 \\
Change $\mathrm{PI}-\mathrm{LL} 1 \mathrm{Y}\left({ }^{\circ}\right)$ & $-3.1 \pm 17.1$ & $-2.4 \pm 15.4$ & 0.780 \\
\hline
\end{tabular}

Values are presented as mean \pm standard deviation.

$\mathrm{SE}$, sacral extension; LF, lumbar fixation; $\mathrm{PI}-\mathrm{LL}$, preoperative pelvic incidence minus lumbar lordosis; change $\mathrm{PI}-\mathrm{LL} \mathrm{YY}$, change of PI- $\mathrm{LL}$ after 1 year compared to baseline.

Table 2. Sagittal alignment before and after surgery in the SE and LF groups

\begin{tabular}{|c|c|c|c|}
\hline Variable & Time & SE & LF \\
\hline \multirow[t]{3}{*}{ Pelvic incidence $\left({ }^{\circ}\right)$} & Preop & $56.8 \pm 13.7$ & $54.3 \pm 13.5$ \\
\hline & $6 w k$ & $56.3 \pm 13.2$ & $54.9 \pm 13.7$ \\
\hline & Follow-up & $56.3 \pm 13.2$ & $54.7 \pm 13.6$ \\
\hline \multirow[t]{3}{*}{ Pelvic tilt $\left({ }^{\circ}\right)$} & Preop & $22.0 \pm 11.0$ & $20.9 \pm 9.5$ \\
\hline & $6 w k$ & $19.9 \pm 10.5$ & $22.1 \pm 11.3$ \\
\hline & Follow-up & $21.3 \pm 9.8$ & $20.1 \pm 10.7$ \\
\hline \multirow[t]{3}{*}{ Sagittal vertical axis (mm) } & Preop & $44.7 \pm 64.1$ & $33.5 \pm 69.1$ \\
\hline & $6 w k$ & $23.3 \pm 44.4$ & $31.1 \pm 62.0$ \\
\hline & Follow-up & $30.4 \pm 63.0$ & $19.7 \pm 60.0$ \\
\hline \multirow{3}{*}{ Lumbar lordosis $\left({ }^{\circ}\right)$} & Preop & $50.8 \pm 20.0$ & $48.0 \pm 21.2$ \\
\hline & 6 wk & $55.9 \pm 14.0$ & $47.4 \pm 18.0$ \\
\hline & Follow-up & $53.2 \pm 15.4$ & $51.0 \pm 18.1$ \\
\hline \multirow[t]{3}{*}{ Thoracic kyphosis $\left({ }^{\circ}\right)$} & Preop & $38.7 \pm 24.7$ & $41.4 \pm 25.9$ \\
\hline & $6 w k$ & $40.1 \pm 14.8$ & $37.8 \pm 17.5$ \\
\hline & Follow-up & $41.1 \pm 18.8$ & $36.8 \pm 16.3$ \\
\hline \multirow[t]{3}{*}{ C7 plumb line (mm) } & Preop & $31.9 \pm 41.2$ & $35.4 \pm 34.1$ \\
\hline & $6 w k$ & $26.2 \pm 21.3$ & $27.3 \pm 26.3$ \\
\hline & Follow-up & $28.5 \pm 22.8$ & $27.1 \pm 23.4$ \\
\hline
\end{tabular}

Values are presented as mean \pm standard deviation.

SE, sacral extension; LF, lumbar fixation; Preop, preoperative. statistically significant $(p=0.013)$.

\section{Spino-pelvic alignment}

PI, PT, lumbar-pelvic mismatch (already included in the propensity match), and SVA were used to describe the sagittal alignment and did not significantly differ between groups at baseline or 1 year after surgery. Similar results were obtained with LL, TK, and the C7 plumb line. The global parameters of spino-pelvic alignment are summarized in Table 2; PI-LL was $6.0^{\circ} \pm 22.7^{\circ}$ preoperatively and $2.9^{\circ} \pm 16.7^{\circ}$ at follow-up for SE and $6.2^{\circ} \pm 20.0^{\circ}$ and $3.7^{\circ} \pm 18.7^{\circ}$ for LF preoperatively and follow-up, respectively.

\section{Proximal junctional kyphosis}

The rate of PJK after 1 year was similar for the SE (30.3\%) and LF groups (22.5\%) ( $p=0.207)$. The mean UIV to $\mathrm{UIV}+2$ angle was $-9.4^{\circ} \pm 25.2^{\circ}(\mathrm{SE})$ and $-9.5^{\circ} \pm 14.8^{\circ}$ (LF) $(p=0.963)$, with a 1 year to baseline difference of $-8.2^{\circ} \pm 21.8^{\circ}(\mathrm{SE})$ and $-8.3^{\circ} \pm 10.1^{\circ}(\mathrm{LF})$ in the PJK angle $(p=0.954)$ (Table 3). A subgroup analysis of patients with PJK after 1 year did not show a significant difference in the SVA between SE $(n=31,12.0 \pm 60.4)$ and LF $(n=23$, $-1.8 \pm 37.3)(p=0.340)$.

For SE patients, the baseline $\left(10.7^{\circ} \pm 19.6^{\circ}\right)$ to 1 year $\left(0.7^{\circ} \pm 18.6^{\circ}\right)$ difference in LL was significantly higher in patients who developed PJK $(p=0.012)$. Moreover, the baseline $\left(-13.2^{\circ} \pm 18.4^{\circ}\right)$ to 1 year $\left(-4.2^{\circ} \pm 13.7^{\circ}\right)$ difference of the TK was significantly lower in patients who developed PJK ( $p=0.014)$. Change in the SVA in PJK-LF patients $(-49.3 \pm 67.5 \mathrm{~mm})$ was significantly higher than in no-PJK patients $(-8.7 \pm 39.5 \mathrm{~mm})(p=0.001)$, which was similar to the results found in PJK-SE $(-43.3 \pm 55.1 \mathrm{~mm})$ and no-PJK $(-12.2 \pm 77.6 \mathrm{~mm})$ patients $(p=0.069)$.

Patients with PJK had similar mean BMIs in the SE

Table 3. PJK angle results 1 year after surgery and their difference to the baseline values

\begin{tabular}{lccc} 
Variable & SE & LF & $p$-value \\
\hline PJK angle at 1 year $\left({ }^{\circ}\right)$ & $-9.4 \pm 25.2$ & $-9.5 \pm 14.8$ & 0.963 \\
\begin{tabular}{l}
$\begin{array}{l}\text { One year to baseline difference } \\
\text { of PJK angle }\end{array}$ \\
\hline
\end{tabular} & $-8.2 \pm 21.8$ & $-8.3 \pm 10.1$ & 0.954 \\
\hline
\end{tabular}

Values are presented as mean \pm standard deviation.

PJK, proximal junctional kyphosis; SE, sacral extension; LF, lumbar fixation. 
(29.7 \pm 7.4$)$ and LF (27.8 \pm 8.9$)$ groups ( $p=0.445)$. There was also no significant difference in BMI between SE and LF patients in the absence of PJK ( $p=0.572)$. To analyze the role of the UIV, we divided the spine into different regions: $\mathrm{C} 1$ to $\mathrm{T} 1, \mathrm{~T} 2$ to $\mathrm{T} 4, \mathrm{~T} 5$ to $\mathrm{T} 8, \mathrm{~T} 9$ to $\mathrm{T} 12$, and $\mathrm{L} 1$ to L5. A significant association between PJK and the UIV between groups could only be found for T9 to T12 ( $n=53)$ with a higher PJK rate observed in the SE $(n=14)$ group compared to the LF $(n=4)$ group $(p=0.026)$. The other subdivisions did not reveal significant associations. Additional interbody fusion did not increase the risk of PJK for SE $(p=0.180)$ or LF $(p=0.243)$ patients.

\section{Health-related quality of life}

Similar baseline values for both the mODI and SRS$22 \mathrm{r}$ total questionnaire were found. The mODI values were similar between SE $(48.0 \pm 20.0)$ and LF $(40.0 \pm 19.8)$ $(p=0.190)$. The baseline SRS-22r total questionnaire was similar between SE $(2.8 \pm 0.7)$ and LF (3.0 \pm 0.7$)(p=0.156)$. After 1 year, the mODI decreased to $33.3 \pm 21.5$ (SE) and $23.6 \pm 18.7$ (LF) $(p=0.007)$, and the SRS-22r total questionnaire increased to $3.3 \pm 0.8$ (SE) and $3.8 \pm 0.8$ (LF) $(p=0.002)$. In the analysis of the mODI and SRS-22r total questionnaire scores after 1 year in the SE and LF groups, no significant differences were found for patients with or without PJK in these groups. The SRS-22r total questionnaire was significantly lower in patients without PJK when instrumented to the ilium ( $3.4 \pm 0.9$ versus $3.8 \pm 0.8$ ) $(p=0.024)$; however, no significant difference was found for the mODI.

\section{Discussion}

In this study, we found that SE during ASD surgery was not a risk factor for PJK, and therefore refuted our hypothesis that the increased rigidity of the construct with a resulting higher load for the UIV+2 would result in higher overall PJK rate following SE. Though, our results contradict previously findings, it should be noted that others including Bridwell et al. [8] focused on the PJK angle in adult scoliosis patients, rather than SE as a potential risk factor for PJK. Inoue et al. [10] showed increased $\mathrm{PJK}$ rates in patients with fusion down to the sacrum after ASD realigning surgery.

In contrast to Inoue et al. [10], our data suggest that $\mathrm{PJK}$ is not generally linked to sacral extension except in patients with an UIV of T9-T12.

Nevertheless, there is evidence that fusion from the sacrum to the upper thoracic spine is associated with higher PJK rates compared to the lower thoracic spine, although not been shown by the results of our study [27]. However, this is still under debate. O'Shaughnessy et al. [28] found a decreased risk (10\% versus 18\%) of PJK when fusing to the upper thoracic spine. Annis et al. [29] performed a retrospective review of 135 cases and performed univariate and multivariate regression analysis. Similar to our data, high rates of PJK were found in patients with an UIV at T10. Instrumentation down to the pelvis was identified as risk factor for PJK [29].

Moreover, because fusion rates after sacral fixation vary considerably. Iliac screws help to offload strain from sacral screws at the lumbopelvic junction after ASD surgery [17-19]. Although it is known from previous studies that iliac screws are beneficial for fusion and protect sacral screws from loosening in spinal deformity surgery, potential problems exist. Lean patients have been reported to complain of implant prominence and focal pain, resulting in the removal of implanted iliac screws in up to $22 \%$ of cases within 2 years, though this may be techniquedependent [13-15].

While the overall rate of PJK was similar for SE and LF patients in our study, analyzing the different UIV levels did show a significantly higher rate of PJK between T9 and T12 after SE compared to LF. Therefore, the risk of PJK after SE in ASD surgery might potentially be higher for low UIV levels. The reason might be that the remaining flexibility of the lower lumbar spine disc spaces, especially L5/S1, after LF protects UIV+2 from strain, causing PJK.

Our study findings contradict the commonly assumed notion of increased PJK rates after SE/pelvic fixation due to increased rigidity, especially when using iliac screws. Instead, an increased PJK rate after SE was found only for UIV levels between T9 and T12. Therefore, our results might support surgeons' tendency to use SE, at least in constructs involving the upper thoracic spine, instead of, for example, stopping at L5 with an increased risk for postoperative adjacent disc disease at this level [17-19].

Many risk factors have been identified to be associated with the development of PJK; however, development of prediction models is still in early stages with individual precise prediction remaining difficult so far [30].

Although this study involved comprehensive propensity 
matching, the methodology has limitations. We included patients with 1 year postoperative follow-up following ASD surgery. Though most PJK cases should have been detected within this period, it is plausible that a few cases were overlooked. Propensity matching was based on a sample size that was restricted to two databases, one with prospective data and the other with retrospective data. Additionally, with our limited knowledge of PJK, it is currently impossible to match for all risk factors. Moreover, we do not present data on the clinical relevance of PJK in our patient cohort.

\section{Conclusions}

This study focused on the role of SE in ASD surgery related to the potential risk for the development of PJK. We found that in a propensity-matched set of patients, SE increased the risk for PJK only with UIV levels at T9-T12 compared to LF. However, sacral fixation in our study was not a general risk factor for PJK.

\section{Conflict of Interest}

No potential conflict of interest relevant to this article was reported.

\section{References}

1. Kim YJ, Bridwell KH, Lenke LG, Glattes CR, Rhim S, Cheh G. Proximal junctional kyphosis in adult spinal deformity after segmental posterior spinal instrumentation and fusion: minimum five-year follow-up. Spine (Phila Pa 1976) 2008;33:2179-84.

2. Lau D, Clark AJ, Scheer JK, et al. Proximal junctional kyphosis and failure after spinal deformity surgery: a systematic review of the literature as a background to classification development. Spine (Phila Pa 1976) 2014;39:2093-102.

3. Yagi M, Rahm M, Gaines R, et al. Characterization and surgical outcomes of proximal junctional failure in surgically treated patients with adult spinal deformity. Spine (Phila Pa 1976) 2014;39:E607-14.

4. Cho SK, Shin JI, Kim YJ. Proximal junctional kyphosis following adult spinal deformity surgery. Eur Spine J 2014;23:2726-36.

5. Glattes RC, Bridwell KH, Lenke LG, Kim YJ, Rinella A, Edwards C 2nd. Proximal junctional kyphosis in adult spinal deformity following long instrumented posterior spinal fusion: incidence, outcomes, and risk factor analysis. Spine (Phila Pa 1976) 2005;30:1643-9.

6. Kim HJ, Bridwell KH, Lenke LG, et al. Patients with proximal junctional kyphosis requiring revision surgery have higher postoperative lumbar lordosis and larger sagittal balance corrections. Spine (Phila $\mathrm{Pa}$ 1976) 2014;39:E576-80.

7. Yagi M, Akilah KB, Boachie-Adjei O. Incidence, risk factors and classification of proximal junctional kyphosis: surgical outcomes review of adult idiopathic scoliosis. Spine (Phila Pa 1976) 2011;36:E60-8.

8. Bridwell KH, Lenke LG, Cho SK, et al. Proximal junctional kyphosis in primary adult deformity surgery: evaluation of 20 degrees as a critical angle. Neurosurgery 2013;72:899-906.

9. Yagi M, King AB, Boachie-Adjei O. Incidence, risk factors, and natural course of proximal junctional kyphosis: surgical outcomes review of adult idiopathic scoliosis: minimum 5 years of follow-up. Spine (Phila Pa 1976) 2012;37:1479-89.

10. Inoue S, Khashan M, Fujimori T, Berven SH. Analysis of mechanical failure associated with reoperation in spinal fusion to the sacrum in adult spinal deformity. J Orthop Sci 2015;20:609-16.

11. Kim YJ, Bridwell KH, Lenke LG, Kim J, Cho SK. Proximal junctional kyphosis in adolescent idiopathic scoliosis following segmental posterior spinal instrumentation and fusion: minimum 5-year followup. Spine (Phila Pa 1976) 2005;30:2045-50.

12. Kim HJ, Yagi M, Nyugen J, Cunningham ME, Boachie-Adjei O. Combined anterior-posterior surgery is the most important risk factor for developing proximal junctional kyphosis in idiopathic scoliosis. Clin Orthop Relat Res 2012;470:1633-9.

13. Balderston RA, Winter RB, Moe JH, Bradford DS, Lonstein JE. Fusion to the sacrum for nonparalytic scoliosis in the adult. Spine (Phila Pa 1976) 1986;11:824-9.

14. Boachie-Adjei O, Dendrinos GK, Ogilvie JW, Bradford DS. Management of adult spinal deformity with combined anterior-posterior arthrodesis and Luque-Galveston instrumentation. J Spinal Disord 1991;4:131-41.

15. Devlin VJ, Boachie-Adjei O, Bradford DS, Ogilvie JW, Transfeldt EE. Treatment of adult spinal deformity with fusion to the sacrum using CD instrumen- 
tation. J Spinal Disord 1991;4:1-14.

16. Rechtine GR, Sutterlin CE, Wood GW, Boyd RJ, Mansfield FL. The efficacy of pedicle screw/plate fixation on lumbar/lumbosacral autogenous bone graft fusion in adult patients with degenerative spondylolisthesis. J Spinal Disord 1996;9:382-91.

17. Farcy JP, Rawlins BA, Glassman SD. Technique and results of fixation to the sacrum with iliosacral screws. Spine (Phila Pa 1976) 1992;17(6 Suppl):S190-5.

18. Kuklo TR, Bridwell KH, Lewis SJ, et al. Minimum 2-year analysis of sacropelvic fixation and L5-S1 fusion using S1 and iliac screws. Spine (Phila Pa 1976) 2001;26:1976-83.

19. Tsuchiya K, Bridwell KH, Kuklo TR, Lenke LG, Baldus C. Minimum 5-year analysis of L5-S1 fusion using sacropelvic fixation (bilateral S1 and iliac screws) for spinal deformity. Spine (Phila Pa 1976) 2006;31:303-8.

20. Wang H, Ding W, Ma L, Zhang L, Yang D. Prevention of proximal junctional kyphosis: are polyaxial pedicle screws superior to monoaxial pedicle screws at the upper instrumented vertebrae? World Neurosurg 2017;101:405-15.

21. Rillardon L, Levassor N, Guigui P, et al. Validation of a tool to measure pelvic and spinal parameters of sagittal balance. Rev Chir Orthop Reparatrice Appar Mot 2003;89:218-27.

22. Rajnics P, Pomero V, Templier A, Lavaste F, Illes T. Computer-assisted assessment of spinal sagittal plane radiographs. J Spinal Disord 2001;14:135-42.

23. Daltroy LH, Cats-Baril WL, Katz JN, Fossel AH, Liang $\mathrm{MH}$. The North American Spine Society lumbar spine outcome assessment Instrument: reliability and validity tests. Spine (Phila Pa 1976) 1996;21:741-9.

24. Asher MA, Lai SM, Glattes RC, Burton DC, Alanay A, Bago J. Refinement of the SRS-22 health-related quality of life questionnaire function domain. Spine (Phila Pa 1976) 2006;31:593-7.

25. Joshi VD, Raiturker PP, Kulkarni AA. Validity and reliability of English and Marathi Oswestry Disability Index (version 2.1a) in Indian population. Spine (Phila Pa 1976) 2013;38:E662-8.

26. Helenius I, Lamberg T, Osterman K, et al. Posterolateral, anterior, or circumferential fusion in situ for high-grade spondylolisthesis in young patients: a long-term evaluation using the Scoliosis Research Society questionnaire. Spine (Phila Pa 1976) 2006;31:190-6.

27. Sebaaly A, Sylvestre C, El Quehtani Y, et al. Incidence and risk factors for proximal junctional kyphosis: results of a multicentric study of adult scoliosis. Clin Spine Surg 2018;31:E178-83.

28. O' Shaughnessy BA, Bridwell KH, Lenke LG, et al. Does a long-fusion “T3-sacrum” portend a worse outcome than a short-fusion "T10-sacrum" in primary surgery for adult scoliosis? Spine (Phila Pa 1976) 2012;37:884-90.

29. Annis P, Lawrence BD, Spiker WR, et al. Predictive factors for acute proximal junctional failure after adult deformity surgery with upper instrumented vertebrae in the thoracolumbar spine. Evid Based Spine Care J 2014;5:160-2.

30. Sebaaly A, Riouallon G, Obeid I, et al. Proximal junctional kyphosis in adult scoliosis: comparison of four radiological predictor models. Eur Spine J 2018;27:613-21. 